\title{
WADAH AKTIVITAS DAN KOMUNITAS DI CENGKARENG, JAKARTA
}

\author{
Angel Valencia ${ }^{1)}$ \\ 1) Program Studi S1 Arsitektur, Fakultas Teknik, Universitas Tarumanagara,angelvalen17@yahoo.co.id

\begin{abstract}
Abstrak
Cengkareng merupakan kecamatan dengan jumlah pendatang tertinggi di Jakarta dan dengan jumlah penduduk yang padat. Memungkinkan adanya komunitas-komunitas baru yang akan hadir. Kurangnya terfasilitasi tempat third place bagi warga Cengkareng sehingga warga sering menghabiskan waktu luang untuk berkumpul di sebelah pemakaman. Mushollah menjadi tempat berkumpul warga untuk beribadah atau sekedar menghabiskan waktu bersama. Third place bagi masyarakat kota berfungsi sebagai ruang antara ruang yang tempat tinggal dan ruang tempat bekerja. Third place membantu masyarakat kota agar bersifat humanis, terbuka, dinamis dan produktif. Manusia sebagai makhluk sosial membutuhkan interaksi sosial dalam menjalani kehidupan. Dengan adanya bangunan wadah komunitas dan aktivitas yang berfungsi sebagai wadah interaksi sosial bagi masyarakat Cengkareng dapat membuat warga sekitar untuk saling mengenal dan mengetahui mengenai kegiatan yang ada di Cengkareng. Kemudian dapat mengurangi adanya masalah individualisme dan vandalisme yang berada di Cengkareng. Desain bangunan akan berpacu pada tiga fungsi utama bangunan yaitu sosial, rekreasi dan edukasi dengan konsep bangunan meletakan plaza menjadi penghubung utama yang terkoneksi dengan fungsi-fungsi tersebut. Diharapkan bangunan ini dapat bermanfaat bagi masyarakat untuk kebaruan mengatasi rasa kebosanan, membuka sudut pandang perspektif baru dan dapat berinteraksi berkenalan dengan orang baru.
\end{abstract}

Kata kunci: Cengkareng; interaksi sosial; ruang interaksi

\begin{abstract}
Cengkareng is a district with the highest number of migrants in Jakarta and with a dense population. Enabling new communities to come. The lack of facilities is facilitated for third place residents of Cengkareng so residents often spend free time to gather next to the cemetery. Mushollah is a gathering place for residents to worship or just spend time together .hird place for the city community functions as a space between the living space and work space. Third place helps urban people to be humanistic, open, dynamic and productive. Humans as social beings need social interaction in living life. With the existence of a community forum building and activities that function as a forum for social interaction for the people of Cengkareng, it can make the local residents get to know each other and know about the activities in Cengkareng. Then it can reduce the problems of individualism and vandalism that are in Cengkareng. The building design will be based on the three main functions of the building, namely social, recreational and education with the concept of the building placing the plaza as the main link connected with these functions. It is hoped that this building can be useful for the community to deal with a new sense of boredom, open up new perspectives and interact with new people.
\end{abstract}

\section{Keywords: Cengkareng; interaction space; social interaction}

\section{PENDAHULUAN}

Third place bagi masyarakat kota berfungsi sebagai ruang antara ruang yang tempat tinggal dan ruang tempat bekerja. Third place membantu masyarakat kota agar bersifat humanis, terbuka, dinamis dan produktif oleh karena itu third place disebut juga sebagai a public meeting place oleh Larice dan Macdonad. Manusia sebagai makhluk sosial membutuhkan interaksi sosial dalam menjalani kehidupan. Ruang publik sendiri merupakan suatu syarat agar suatu kota 
menjadi kota layak huni. Setiap budaya mempengaruhi masyarakat dalam menggunakan ruang kota sehingga antar kota pun terdapat karakteristiknya masing-masing.

Di Cengkareng sendiri keberadaan ruang publik terhitung cukup kurang untuk mewadahi kegiatan masyarakat untuk berinteraksi sosial hal itu dapat dilihat dengan adanya beberapa warga yang memilih untuk menghabiskan waktu luangnya dengan cara berkumpul dan berinteraksi di sebelah pemukiman dan menjadikan mushollah sebagai tempat ibadah sekaligus tempat berkumpul untuk bersosialisasi. Bahkan gang-gang/ trotoar yang dapat menjadi ruang publik difungsikan sebagai tempat parkir dan tempat berjualan.

Kurangnya interaksi sosial antar masyarakat dapat disebabkan oleh pengaruh teknologi dan alur kehidupan yang monoton setiap harinya (first place-second place). Sehingga dapat menyebabkan rasa individualis yang tinggi antar masyarakat dan dan menimbulkan rasa ketidakpedulian masyarakat dengan apa yang terjadi di lingkunganya. Selain itu kurangnya interaksi sosial pada kependudukan perkampugan padat menyebabkan ketiadaan lahan bermain, pengaruh lingkungan yang kurang terarah dan tindakan premanisme dan adanya aksi vandalisme hal itu terlihat dari adanya tembok yang berserakan sampah karena penuh coretan dari cat semprot di sudut-sudut gang dan tanah kosong oleh remaja-remaja sehabis pulang sekolah.

Dibutuhkan third place agar tidak terjadi degradasi lingkungan dan sosial terhadap masyarakat dengan adanya ruang publik untuk mewadahi komunitas-komunitas dan aktivitas yang ada di Cengkareng. Proyek ini berfokus untuk menjadikan wadah interaksi sosial, edukasi dan rekreasi bagi masyarakat Cengkareng yang bertujuan untuk memberikan manfaat agar masyarakat dapat beriteraksi dan menemukan teman baru , tidak mengalami kebosanan dalam menjalankan kegiatan dan dapat melihat perspektif baru dari sudut pandang orang lain.

\section{KAJIAN LITERATUR}

\section{Third place}

Open Architeture, merupakan third place bagi masyarakat kota yang berfungsi sebagai ruang antara, ruang yang bukan tempat tinggal (home) dan bukan tempat kerja. The third place adalah sebuah program yang akan membantu masyarakat kota agar bersifat humanis, terbuka, dinamis dan produktif. Open city adalah upaya para arsitek dan perancang kota untuk menciptakan "Masyarakat Terbuka" dengan pemerintah yang toleran dan inklusif, dimana beragam kelompok mengembangkan mekanisme yang fleksibel dengan berbagai perbedaan. Dengan tempat dimana berbagai latar belakang dapat hidup berdampingan. Menurut Ray Oldenburg third place dapat memperkuat rasa kebersamaan masyarakat, kemudian third place adalah tempat dimana orang menghabiskan waktu antara rumah "first place" dan bekerja "second place" dimana masyarakat dapat bertukar ide, bersenang-senang dan membangun hubungan.

Manfaat Third place

a. Kebaruan , tidak mengalami kebosanan karna banyak menemukan banyak hal baru

b. Harbors a Diverse Population (sifat yang berbeda)

c. Lack of Scheduling and Organization ( tidak ada keharusan untuk datang dan siapapun dapat datang ke third place)

d. Emerges Out of The Collective Ability of That Assembly to Create It.

(Tempat ketiga sebagian besar adalah dunia buatannya sendiri, dibuat dengan cara bicara dan cukup independen dari tatanan kelembagaan masyarakat yang lebih besar. Jika dunia tempat ketiga jauh lebih tidak penting daripada dunia yang lebih besar, pelanggan tetapnya akan menemukan banyak kompensasi dalam kenyataan bahwa dunia ini lebih layak, lebih mencintai orang-orang demi kepentingan mereka sendiri, dan, jam demi jam, hebat kesepakatan lebih menyenangkan.)

e. Perspective

Melihat perspektif yang berbeda (kebutuhan sosial masing-masing) walaupun hubungan sosialnya sedikit. Misalnya orangtua yang lebih membutuhkan hubungan sosial, karena orangtua sering mengalami ketakutan irasional. Sama seperti tubuh membutuhkan asupan 
yang seimbang, demikian juga pikiran. Iritasi pada kehidupan modern menuntut jenis pengalaman penyeimbang untuk pergaulan manusia yang menyenangkan dan memuaskan karena kehadiran orang lain. Pandangan tentang kehidupan ditegaskan di sana dan, karena berevolusi dari ketidaktertarikan yang mustahil dalam pengaturan rumah dan pekerjaan, itu adalah yang sangat berharga.

f. Spiritual Tonic

Dapat membangkitkan semangat pengunjung yang datang. Georg Simmel, menyarankan tiga kata yang, jika disatukan, mungkin menyampaikan kualitasnya. Pilihannya adalah kegembiraan, kelincahan, dan kelegaan. Ini menunjukkan sikap pikiran yang luas dan inklusif dan kecenderungan semangat yang menyambut semua usia, jenis kelamin, dan kebangsaan. Asosiasi tempat ketiga optimis karena kebebasan berekspresi yang didorongnya.

g. Friends by the Sets

Menemukan teman baru yang dapat untuk menghibur diri bersama-sama. Mereka yang mempelajari kesepian manusia umumnya setuju bahwa individu membutuhkan hubungan intim dan bahwa ia juga membutuhkan afiliasi. Menjadi afiliasi berarti menjadi anggota beberapa klub, grup, atau organisasi. Apa yang hilang dari masyarakat modern dalam kegagalannya untuk berkembang biak di tempat ketiga adalah versi persahabatan dan pengertian yang lebih mudah yang dihasilkan dari afiliasi kasual dan informal.

\section{Komunitas}

Komunitas terbentuk dari sekelompok orang, saling berinteraksi secara sosial di antara anggota kelompok, berdasarkan adanya kesamaan kebutuhan atau tujuan dalam diri mereka atau di antara anggota kelompok yang lain dan adanya wilayah-wilayah individu yang terbuka untuk anggota kelompok yang lain (Hillery, 1995). Pusat komunitas adalah suatu fasilitas berupa tempat berkumpulnya orang-orang yang memiliki visi dan tujuan yang sama. Pada sebuah komunitas ditemukan dua hal utama yaitu kesamaan dan indentitas. Selain itu terdapat sikap berbagi , partisipasi dan felllowship. Komunitas terbentuk karena adanya ketertarikan yang sama. Komunitas dapat dibedakan berdasarkan pola, atas dasar ukuran (besar dan kecil), atas dasar level (lokal, nasional, internasional), nyata atau tidak nyata(virtual), Komunitas dibedakan menjadi 3 komponen, yaitu berdasarkan lokasi/tempat, dalam komponen ini sebuah komunitas terbentuk karena adanya interaksi di antara beberapa orang/kelompok yang tinggal di wilayah yang sama. Berdasarkan minat, komunitas ini terbentuk karena adanya interaksi orang-orang karena adanya minat yang sama pada satu bidang tertentu. Misalnya komunitas musik, komunitas seni, komunitas pecinta alam dan sebagainya. Berdasarkan hal tersebut komunitas ini adalah komunitas yang terbentuk berdasarkan ide-ide tertentu yang menjadi landasan dari komunitas itu sendiri. (Wikipedia, 2016)

\section{Fungsi dan Manfaat Community center}

Meningkatkan kapasitas Civil Society. Community center bersama lembaga pendukung juga dapat menyokong penguatan kapasitas di bidang keuangan maupun program, selain juga fasilitasi bagi terbangunnya jaringan antar organisasi sejenis di wilayah tersebut. Menggali Potensi Sumber Daya Lokal. Penggalangan atau mobilisasi yang dilakukan akan mendekatkan sumber daya, langsung kepada masyarakat penerima manfaat dan diharapkan mampu memberikan dampak terbesar bagi penyelesaian masalah-masalah yang dihadapi oleh masyarakat.Mendorong Keterlibatan Sektor Swasta. Pengakuan pada konsep pembangunan berkelanjutan berimplikasi pada adanya tiga tujuan dunia usaha, yaitu tujuan ekonomi, sosial dan lingkungan. Tujuan ekonomi pun tidak lagi dibatasi menjadi tujuan ekonomi perusahaan semata, melainkan perekonomian masyarakat secara luas.Pelibatan sektor swasta dalam pertumbuhan community center bersama lembaga pendukung merupakan salah satu inovasi penting dalam pemberdayaan masyarakat. 


\section{Perilaku dalam Konteks Sosial Budaya}

Stainlay Milgram menyatakan bahwa "kita semua adalah makhluk rapuh yang terikat pada jaringan sosial yang membatasi ruang gerak kita" batasan itu berupa : norma, peran dan budaya. Teori atribusi adalah teori yang mengatakan bahwa seseorang termotivasi untuk menjelaskan perilaku mereka sendiri dan orang lain berdasarkan pada faktor situasi (dari lingkungan) maupun disposisi (sifat pribadi). Para psikolog sosial telah mengasumsikan bahwa semua sikap di pelajari,di peroleh dari kelompok dimana seseorang berasal,merupakan pelajaran yang diberikan oleh orang tua dan pengalaman yang dimiliki seseorang,serta mencerminkan keadaan ekonomi,pengaruh sosial,dan lingkungan lainnya. Para peneliti psikologi telah menemukan bahwa beberapa sikap tidak hanya di peroleh dari pembelajaran. Temuan didasarkan pada penelitian behavioral genetics atau genetika perilaku.

Individu dalam kelompok adalah bagaimana kita seharusnya berperilaku ketika kita berada dalam kelompok, apakah kita akan berperilaku berbeda dibandingkan dengan diri kita yang sesungguhnya,terlepas dari apakah kelompok tersebut tujuannya apa,baik itu positif maupun negatif. keputusan dan tindakan yang kita lakukan lebih sedikit dipengaruhi oleh keinginan pribadi kita daripada oleh keputusan yang berasal dari struktur dan dinamika kelompok itu sendiri. Terdapat beberapa sikap ketika individu berada di dalam kelompok:

- Konformitas sosial adalah proses dimana tingkah laku seseorang terpengaruh atau dipengaruhi oleh orang lain di dalam suatu kelompok.

- Etnosentrisme : kepercayaan bahwa budaya anda sendiri,bangsa anda sendiri,atau agama anda sendiri lebih hebat di bandingkan dengan yang lain.

- Stereotip : ringkasan kesan terhadap sekelompok orang dimana semua anggota dalam kelompok dilihat memiliki sifat -sifat yang sama.

\section{METODE}

\section{Pattern Language}

Pada proses peracangan Wadah Aktivitas dan Komunitas di Cengkareng menggunakan metode pattern language. Komposisi dari pattern of event adalah waktu, tempat dan manusia yang saling mempengaruhi. Setiap tempat memiliki karakternya karena memiliki pola peristiwa yang terjadi disana. Hal tersebutlah yang membuat uniknya karakter suatu tempat. Tidak hanya terbentuk dari aktivitas manusia, namun ada pengaruhnya dari keadaan lingkugan. Pengaruh lingkungan yang mendukung adanya events. Dengan adanya pattern of events yang terjadi pada suatu tempat tidak dapat dipisahakan dengan peristiwa yang terjadi peristiwa tersebut karena hal tersebut memiliki ikatan satu sama lain yang menghasilkan karakternya sendiri.
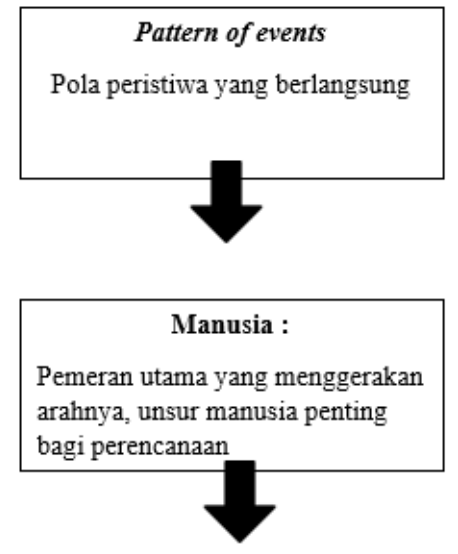

Manusia yang membentuk peristiwa mempengaruhi tempat yang dikunjungi

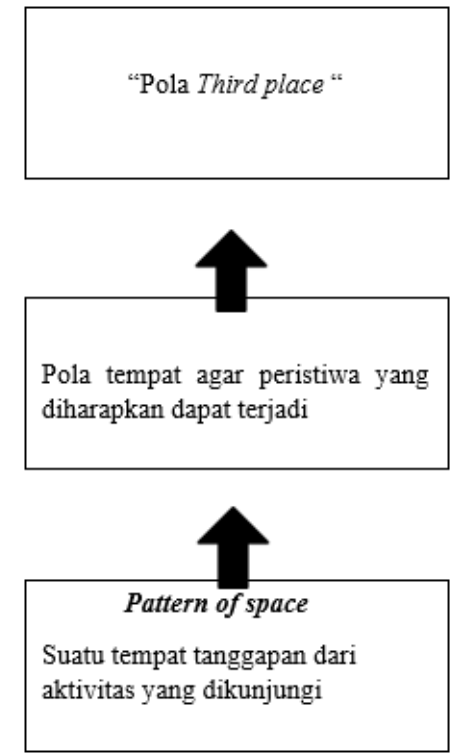




\section{Pendekatan rasional}

Pendekatan intuitif menerapkan konsep kesatuan antara kesakralan ibadah dengan kehidupan manusia sehari-hari, perancangan menitikberatkan pada kesinambungan ruang luar dan ruang arsitektur yang tidak hanya bersifat material. Perancang sebagai pencipta bangunan, hasil perancangan dikendalikan oleh masukan yang diterima terdahulu dan lebih dominan berdasarkan pengalaman. Lebih banyak menggunakan imajinasi dan intuisi, sering merupakan lompatan pemahaman yang sulit ditransformasikan. Kontrol intelegensi mengenai struktur masalah dapat mengakibatkan kesempatan memperoleh hasil yang lebih relevan dengan masalah perancangan.

\section{DISKUSI DAN HASIL}

Wilayah Cengkareng dengan first place (perumahan, kontrakan, kosan dan rumah sewa) dan second placenya berupa pabrik, pergudangan, konveksi, sekolah dan perkantoran. Tempat third place adalah suatu tempat dimana terjadinya suatu interkasi sosial dan komunikasi.Proyek berupa wadah aktivitas dan komunitas bagi warga Cengkareng yang lokasinya berada di antara fungsi perumahan dan fungsi tempat kerja (pabrik dan pergudangan) serta tapak yang dapat diakses oleh kendaraan umum (transjakarta dan statsiun kereta api) sehingga bangunan dapat diakses dengan mudah oleh masyarakat. Konsep proyek adalah mengembangan 3 fungsi utama yaitu sosial, rekreasi dan edukasi dengan konsep bangunan meletakan plaza yang menjadi penghubung utama yang terkoneksi dengan fungsi-fungsi tersebut. Dari pendekatan menggunakan metode kemudian dianalisis dan diolah menjadi pegangan utama dalam mendesain proyek. Dengan membuat sifat ruang menjadi terbuka sehingga pengunjung merasa tidak sengan untuk menghampiri selain itu ruangan terbuka dapat diawasi oleh banyak orang (masalah keamanan). Wadah komunitas dan aktivitas merupakan suatu tempat bagi masyarakat Cengkareng untuk saling berinteraksi dan saling mengenal. Perencanaan wadah komunitas dan aktivitas ini bertujuan agar kawasan Cengkareng memiliki sebuah third place. Third place disini menampung kegiatan dan komunitas yang ada di daerah Cengkareng yang akan membantu masyarakat kota agar bersifat humanis, terbuka, dinamis dan produktif.

\section{Batas dan Ukuran-ukuran pada Tapak}

Cengkareng merupakan kecamatan di daerah khusus Ibukota Jakarta dengan populasi paling banyak. Menurut data Badan Pusat Statistik Jakarta, jumlah penduduk Cengkareng mencapai 494.660 jiwa atau 4,9 persen dari total populasi di Jakarta, yakni 10 juta jiwa pada 2014. Pada tahun 2016, Kelurahan ini dihuni oleh 74.922 penduduk yang terbagi dari 38.035 laki-laki dan 36.887 perempuan dengan seks rasio 103,11 dan 25.593. Merupakan kecamatan yang paling banyak di datangi oleh pendatang karena kawasannya terletak di daerah kawasan pabrik.

Pada pemilihan tapak proyek, tapak yang akan dipilih adalah daerah Jakarta Barat dengan memperkirakan unsur-unsur penunjang yang menjadi kriteria pemilihan tapak yaitu berada di dekat tempat kerja/second place, berada di dekat pemukiman warga, akses yang mudah, transportasi publik dan jalur pedestrian. Tapak dapat diakses oleh kendaraan umum (transjakarta dan statsiun kereta api) 


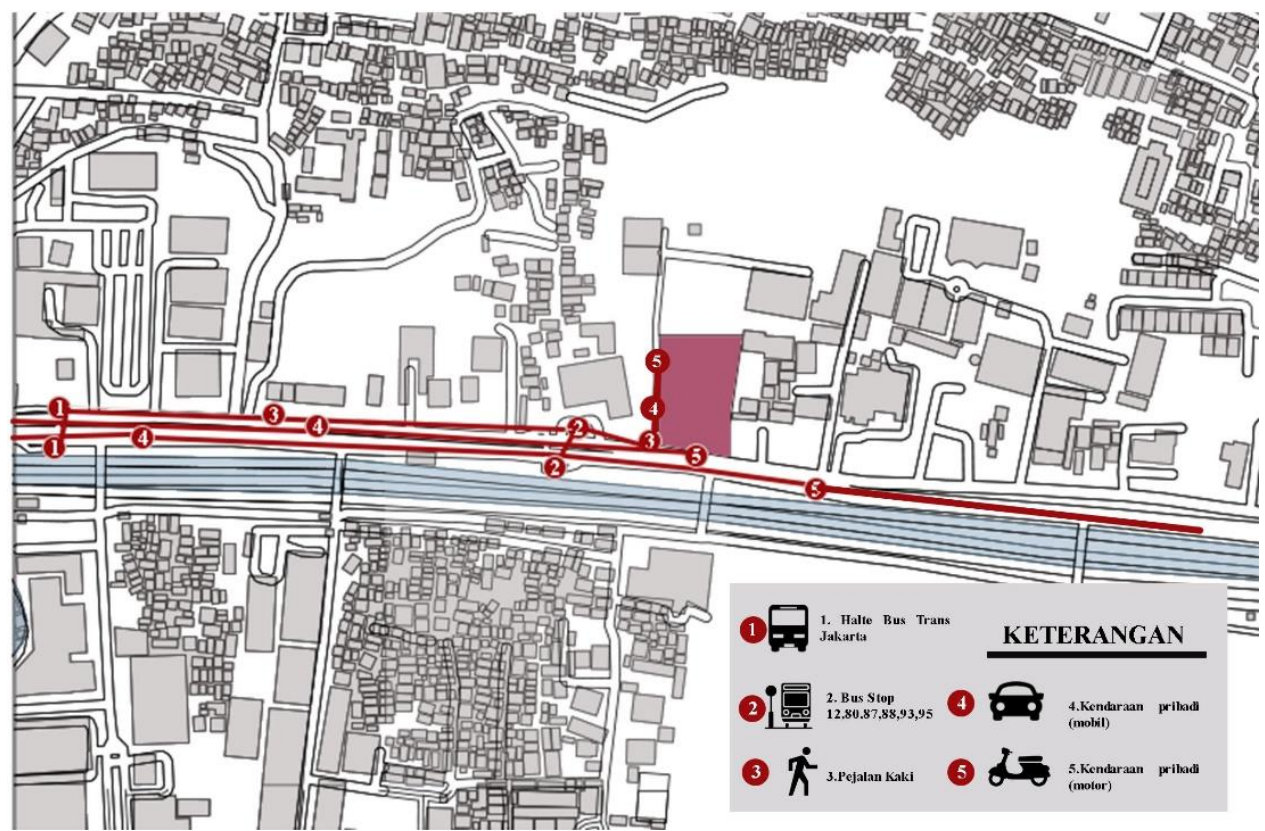

Gambar 1. Analisa Pencapaian

Sumber: Penulis,2019

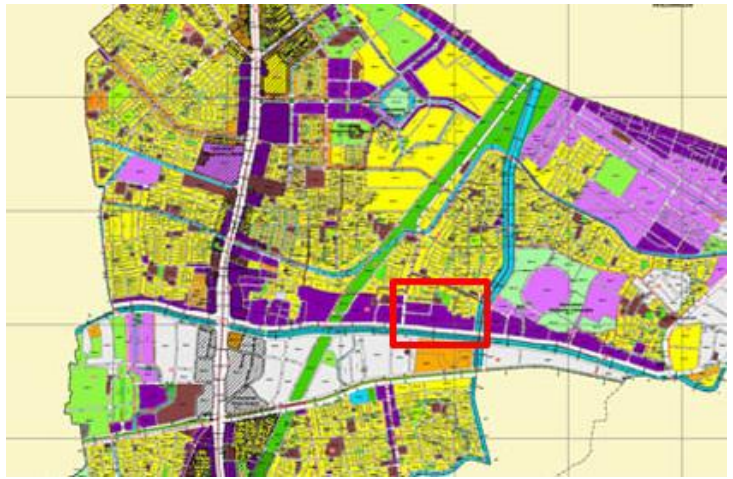

Gambar 2. Peta zonasi Cengkareng

Sumber: Jakartasatu.co.id

Peruntukan

Lokasi : Jalan Daan Mogot

Luas area : $6223 \mathrm{~m}$

Zona : Perkantoran, perdagangan dan jasa.

KDB : 40

Batas Tapak

Utara : Zona hijau

Selatan : Jalan Daan Mogot (Jalan Kolektor )

Timur : Dealer Mobil Mitsubishi Daan Mogot

Barat : CV Sumber Cahaya Diesel

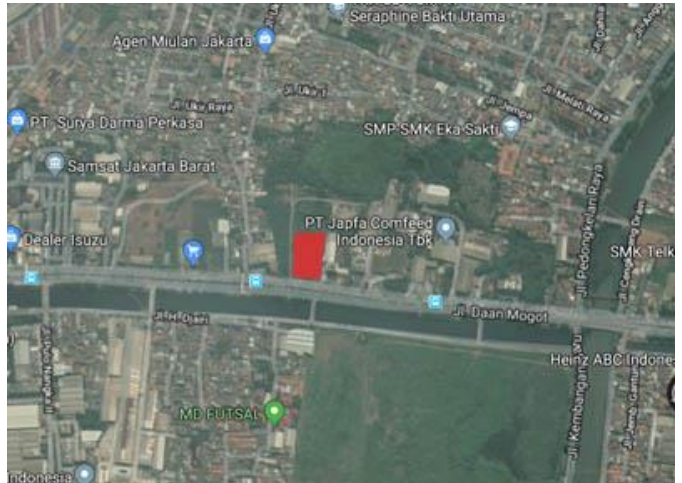

Gambar 3. Keadaan di Tapak

Sumber: Google Map

KTB: 50

$\mathrm{KDH}: 35$

KB: 4

$\mathrm{KLB}: 1,6$ 


\section{E S I G N S C H E M E}
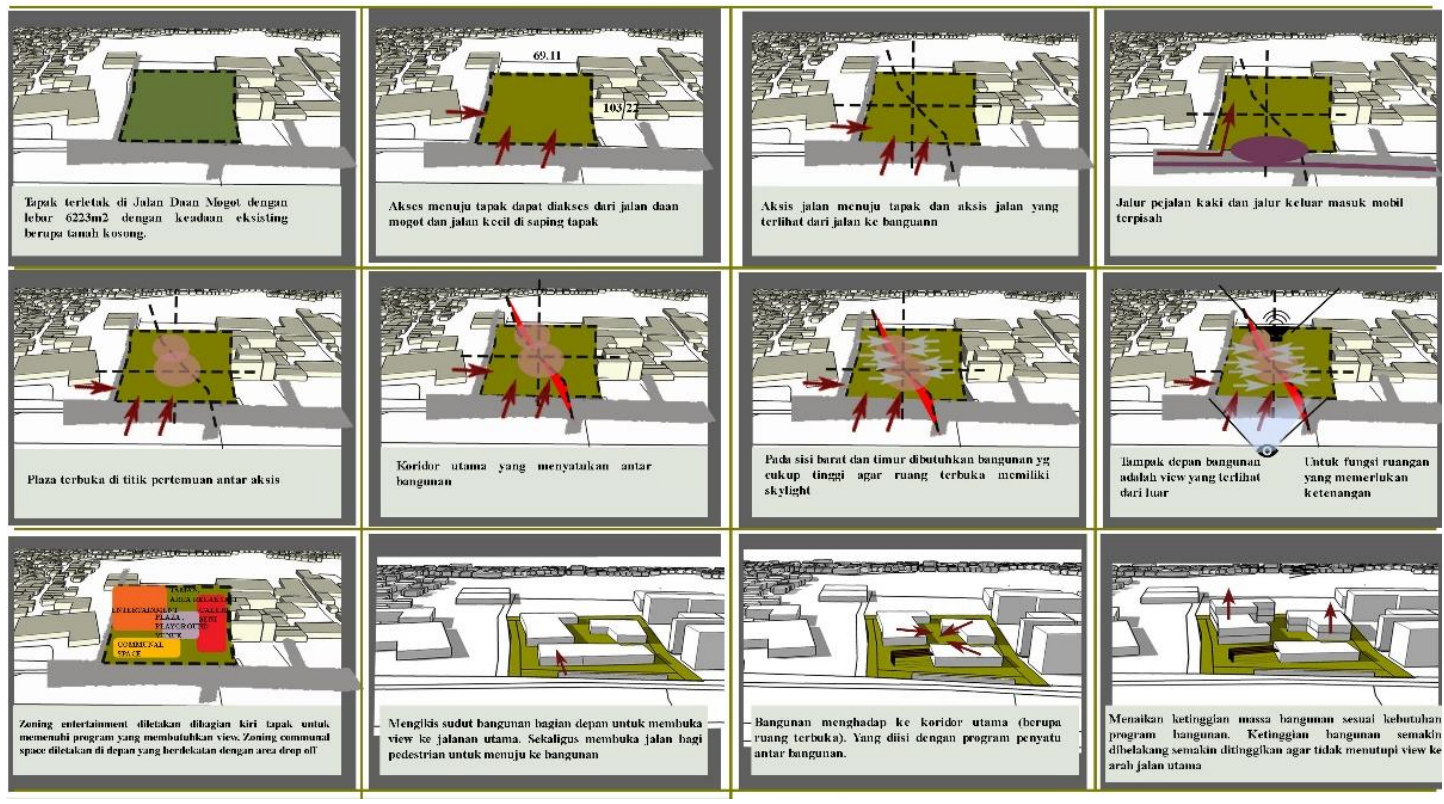

Gambar 4. Design Scheme

Sumber: Penulis, 2019

\section{Design Scheme}

a. Akses menuju tapak yang dapat diakses dari Jalan Daan Mogot dan dari arah samping tapak.

b. Menentukan jalur pejalan kaki dan jalur pejalan kaki agar jalurnya terpisah

c. Peletakan plaza di tengah tapak di titik pertemuan aksis.

d. Koridor yang terkoneksi dengan plaza dan menjadi penghubung antar ruangan.

e. Pada sisi barat dan timur tapak diletakan bangunan yang cukup tinggi agar ruang terbuka memiliki skylight

f. Peletakan zoning yang sesuai dengan kebutuhan masing-masing program. Peletakan program ruang perpustakaan berada di belakang tapak yang jauh dari jalan raya.

g. Ketinggian bangunan diatur agar bangunan terdepan tidak menutupi view bangunan lainnya.

\section{Programming}

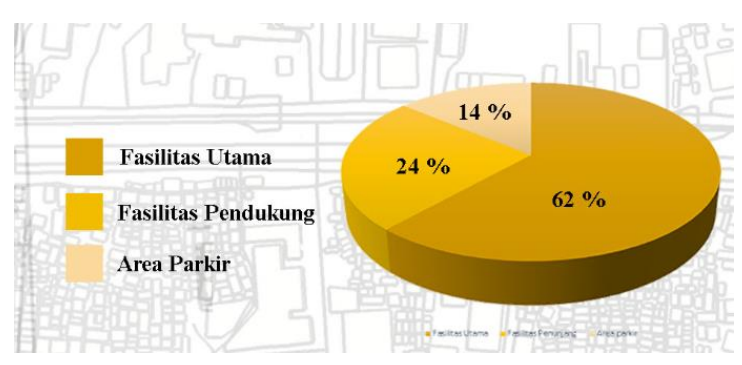

Bangunan wadah komunitas dan aktivitas di Cengkareng,Jakarta terdiri dari 4 lantai. Lantai 1 terdiri dari playground, ruang serba guna, gallery informasi, lobby, mushollah, plaza dan zona anak-anak dengan total luas $2.427,6 \mathrm{~m}^{2}$. Kemudian di lantai 2 terdiri dari kantor pengelola, perpustakaan, ruang baca semi outdoor, play space, studio tari, studio musik dan ruang latihan dengan total luas $2.846,2 \mathrm{~m}^{2}$. Dan dilantai 3 terdiri dari ruang workshop, fitnes dan rooftop garden dengan luas $1.292 \mathrm{~m}^{2}$. Luas basement yang terdiri dari tempat parkir mobil dan motor serta utilitas memiliki luas $1.481 \mathrm{~m}^{2}$. Total luas lantai keseluruhan bangunan sebesar $8.046 \mathrm{~m}^{2}$. 


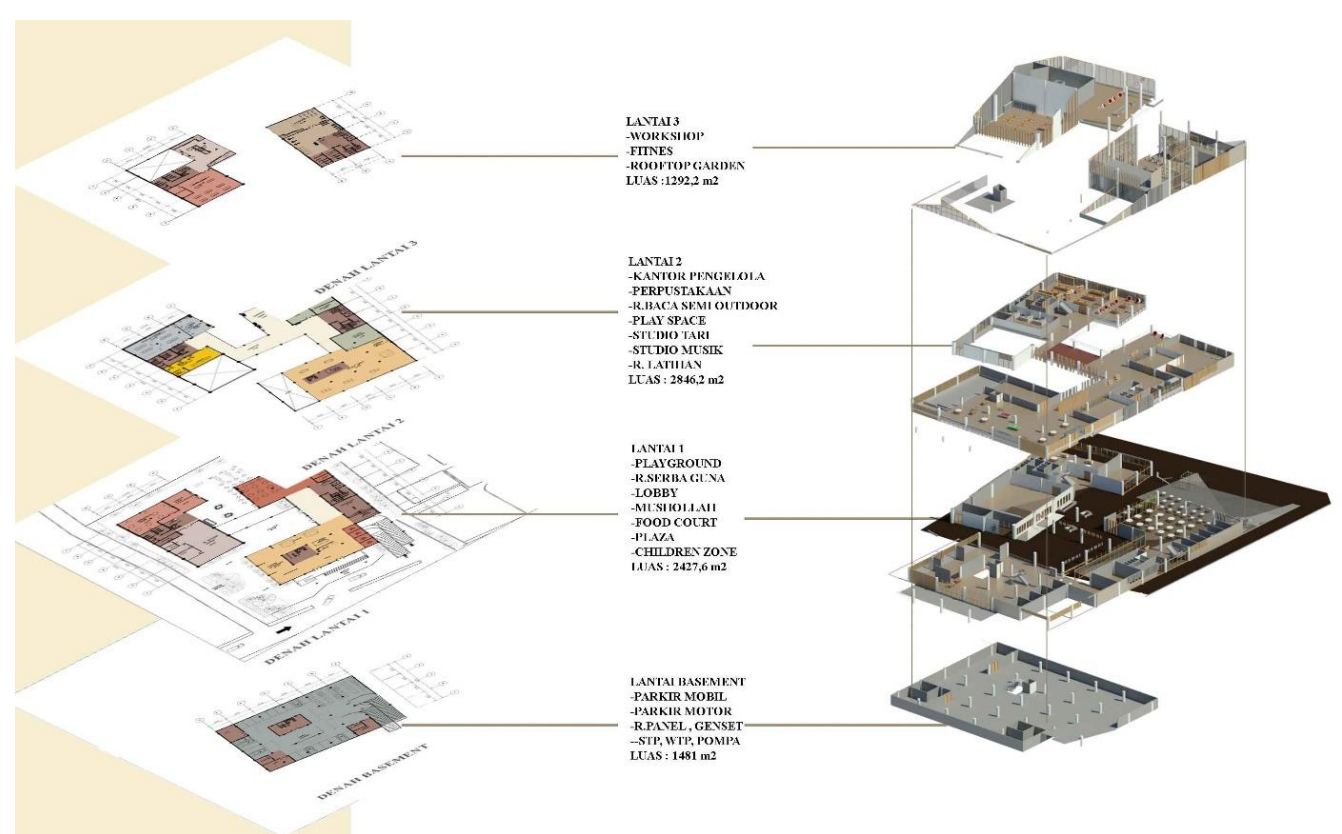

Gambar 5. Eksploded Denah

Sumber: Penulis, 2019

Pada perancangan Wadah Aktivitas dan Komunitas pada lantai dasar difokuskan untuk kegiatan publik yang bersifat lebih umum yaitu dapat diakses oleh semua pengunjung yaitu berupa ruang komersial, plaza, food court, playground dan ruang serba guna. Kemudian untuk lantai kedua dan ketiga massa bangunan di kanan difokuskan untuk kegiatan komunitas warga Cengkareng yang bersifat semi publik berupa ruang latihan tari, ruang latihan musik dan lain-lain. Dan untuk massa bangunan di kiri untuk lantai kedua dan ketiga lebih bersifat umum berupa perpustakaan, ruang baca semi outdoor,workshop dan rooftop garden yang dihubungkan dengan konektor yang dapat melihat ke arah plaza dan playground.
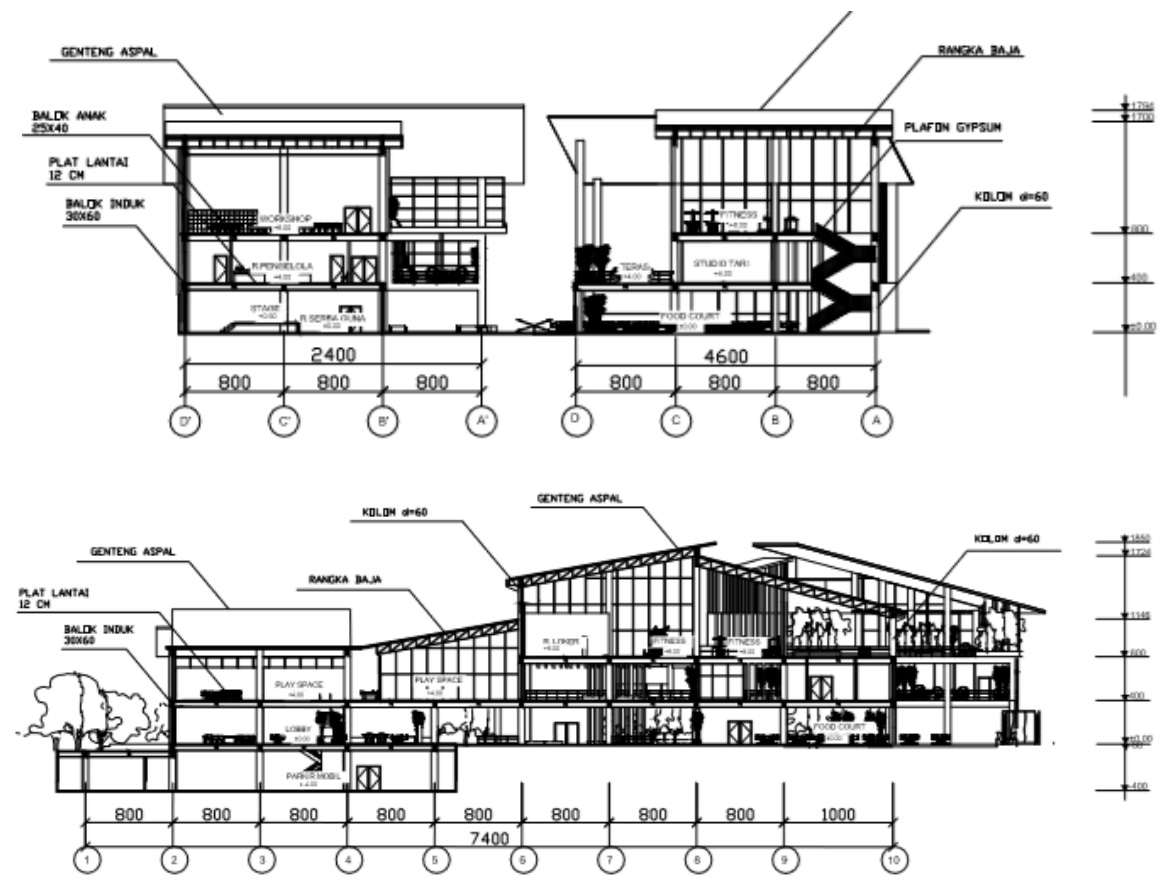

Gambar 6. Potongan Bangunan

Sumber: Penulis,2019 


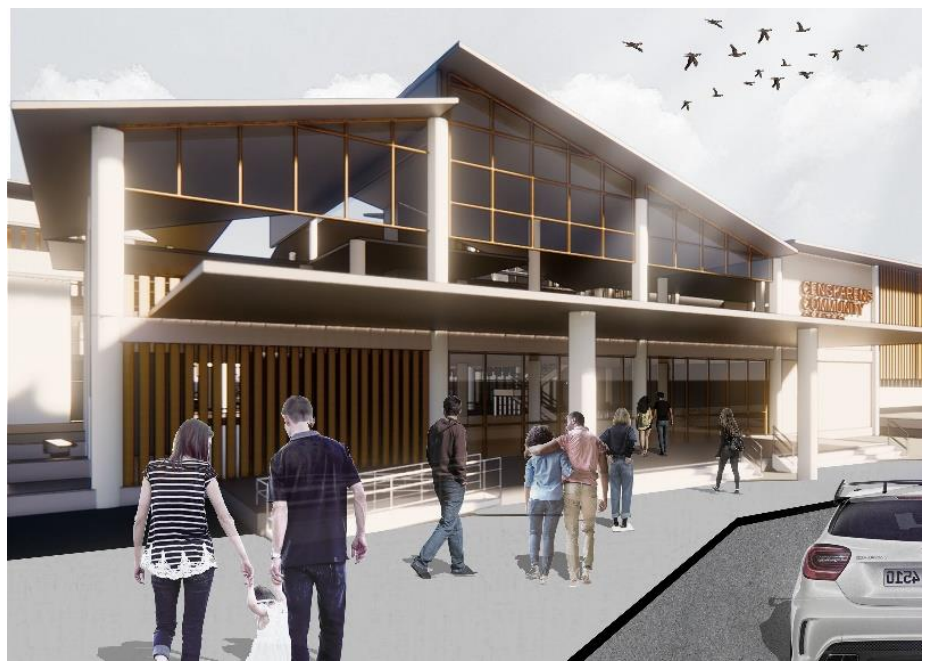

Gambar 7. Perspektif human view

Sumber: Penulis,2019
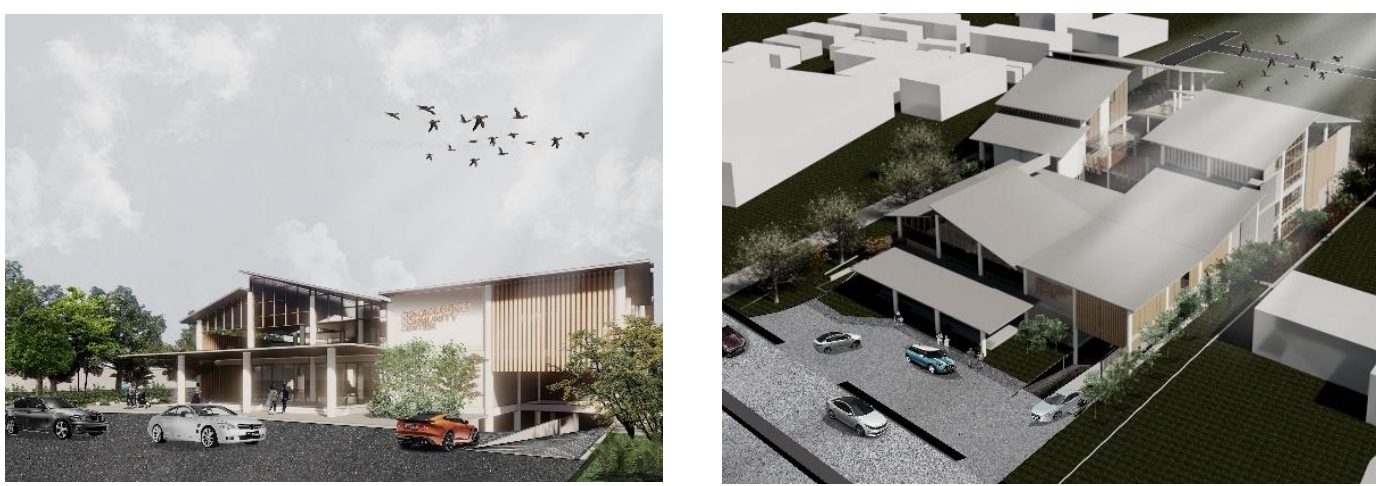

Gambar 8. Perspektif eksterior

Sumber: Penulis, 2019

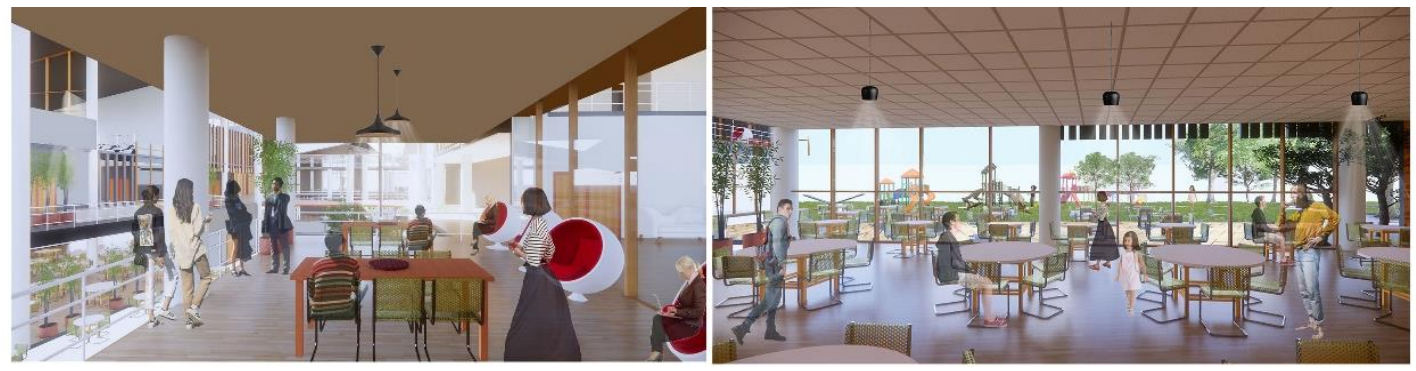

Gambar 9. Interior ruang baca outdoor dan foodcourt Sumber: Penulis,2019

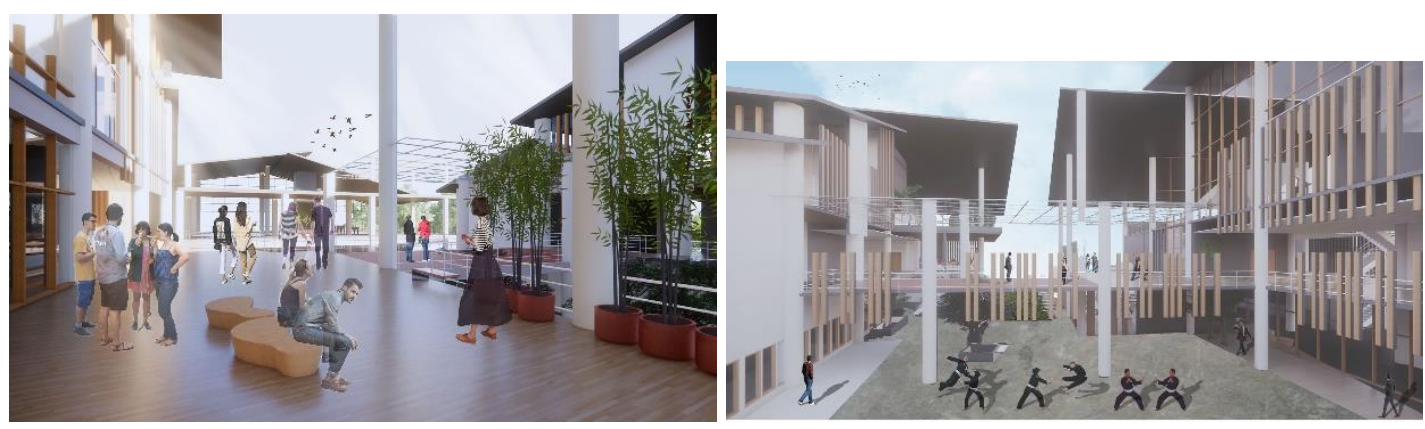

Gambar 10. Interior teras dan plaza bangunan

Sumber: Penulis, 2019 


\section{KESIMPULAN DAN SARAN \\ Kesimpulan}

Kesimpulan yang di dapat fokus utama dalam perancangan ini adalah memberikan third place kepada masyarakat Cengkareng. Dimana menurut pengertian third place adalah suatu tempat yang dapat memperkuat rasa kebersamaan masyarakat (bertukar ide, bersenang-senang, membangun hubungan) untuk melakukan interaksi sosal. Di Cengkareng ruang sosial tidak hanya terjadi di antara penduduk asli Cengkareng namun juga terjadi pada penduduk pendatangnya.Terdapat faktor kebiasaan dan bahasa yang dapat menjadi faktor penghambat dalam interaksi sosial. Fungsi third place disini adalah sebagai tempat berinteraksi masyarakat asli Cengkareng dan masyarakat pendatang agar dapat lebih mengenal bahasa, budaya, kebiasaan, dll. Menjadi sarana sarana sosial yang rekreatif dan edukatif. Dengan menggunakan metode perancangan pattern language yaitu dengan mempelajari lokalitas, sosial, budaya dan iklim wilayah di Cengkareng. Dan dengan melakukan pendekatan intuitif dan rasional yang melibatkan gagasan pribadi perancangan serta peran aktif pengguna (user). Dalam perancangan Wadah Aktivitas dan Komunitas di Cengkareng, Jakarta adalah menjadi suatu tempat untuk masyarakat Cengkareng agar lebih mengenal lingkungannya dan dapat menjadi tempat dimana menjadi tempat interaksi sosial yang netral dan equality yang bermanfaat untuk kebaruan agar masyarakat tidak mengalami kebosanan karena menemukan hal baru, membuka sudut perspektif baru dan dapat menemukan teman baru dan dapat menghibur diri bersama-sama.

\section{Saran}

Adanya saran penambahan program-program yang ada di bangunan wadah aktivitas dan komunitas di Cengkareng, Jakarta diharapkan dapat menampung lebih banyak warga Cengkareng dalam beraktivitas dan berinteraksi sosial. Penambahan program dapat menambah variasi kegiatan dalam bangunan dan dapat menjadi daya tarik yang lebih besar lagi bagi masyarakat untuk datang dan berkegiatan di bangunan wadah aktivitas dan komunikasi di Cengkareng, Jakarta.

\section{REFERENSI}

Alexander, C. (1979). A Pattern Language. New York : Oxford University Press.

Hasyyati, A. Y., Eddy, P., Atiek, S., B. (2012). Community Center di BSD City.

Husein, A. (2016). Pembelajaran Kursus Menjahit di Lembaga Kursus dan Pelatihan di Kabupaten Kudus.

Lestari, L. (2012). Penerapan Pattern Language Tempat Relaksasi Pada Rumah Sebagai Pengembalian Makna Rumah.

Mustikawati, A. (2018). Adaptasi Lingkungan Masyarakat Pendatang Dalam Cerita Rakyat Bontang.

Oldenburg, R. (1989). The Great Good Place. Paragon House

Paturusi, S. A. (2016). Segregasi Ruang Sosial Antara Pendatang degan Penduduk Asli pada Pemukiman Perkotaan di Denpasar.

Rossi, A. (1981). The Architecture of the City". New York : The MIT Press

Utami, L. S. S. (2015). Teori-Teori Adaptasi Antar Budaya. Jurnal Komunikasi Universitas Tarumanagara 7 (2). 180-197

https://id.wikipedia.org/wiki/Ekonomi_kreatif

https://www.maxmanroe.com/vid/bisnis/ekonomi-kreatif.html

https://www.archdaily.com/920857/blue-heart-youkong-living-room-wutopia-lab

https://www.archdaily.com/887675/guardian-art-center-in-beijing-buro-ole-scheeren

https://www.kompasiana.com/iji/59ad07bb20f5c304847bcab2/perbedaan-penjahit-konveksidan-garmen

https://www.indonesiana.id/read/126266/konveksi-pakaian-adalah-istilah-pengertiankonveksi-pakaian 
https://docplayer.info/30571459-Memahami-perilaku-komunikasi-dalam-adaptasi-budayapendatang-dan-hostculture-berbasis-etnisitas.html

https:// instrukturketerampilan.blogspot.com

http://bappeda.jogjaprov.go.id/dataku/sdgs

https://megapolitan.kompas.com/read/2013/09/20/2323444/Kota.Layak.Huni.Harus.Punya.Ba nyak.Ruang.Publik

https://www.kompasiana.com/dwiatmoko/5badd649ab12ae131404fff5/vandalisme-

sempitnya-ruang-sosial-dan-ketidakpedulian-masyarakat?page=all 
